\title{
Proposta de melhoria no processo de logística reversa de óleos lubrificantes usados ou contaminados
}

\section{Proposal for improvement in the reverse logistics process of lubricating oils used or contaminated}

\author{
1 Erik Telles Pascoal _erik.pascoal@outlook.com \\ 1 Lara Nabak Maroti Ribeiro \\ 1 Rafael Mendes
}

1 Universidade Federal de Alfenas (UNIFAL)

\section{Resumo}

Qualquer produto acabado gera algum tipo de resíduo ou refugo ao final de sua vida útil. Atualmente, um produto de extensa aplicação e que gera resíduo com um potencial poluidor muito alto é o óleo lubrificante. A alternativa correta para o destino desse óleo lubrificante usado ou contaminado (OLUC) é a realização de sua logística reversa por meio de seu rerrefino. Este estudo teve como objetivo avaliar o processo de logística reversa dos OLUCs no município de Poços de Caldas-MG. Para esse fim, os procedimentos técnicos utilizados foram pesquisa bibliografia, visita técnica e entrevistas. A análise desse processo apontou uma oportunidade de melhoria, que é a mudança do local de realização dos testes de pré-rerrefino, que poderá ser feita na origem da coleta (Poços de Caldas) e não mais no final (na Rerrefinadora). Identificou-se, ainda, a possibilidade de uma empresa júnior da Universidade Federal de Alfenas - campus de Poços de Caldas realizar os testes necessários para aptidão do OLUC ao rerrefino. Tal proposta significa ganho para todas as partes da cadeia do produto: produtores, consumidores, coletores, rerrefinadores, comunidade acadêmica e, é claro, o meio ambiente.

\section{Palavras-chave:}

Logística reversa. Óleos lubrificantes usados ou contaminados. Rerrefino. Empresa Júnior.

\begin{abstract}
Any finished product generates some type of residue at the end of its useful life. Currently, a product of extensive application and that generates a residue with a very high polluting potential is lubricating oil. The correct alternative for the destination of this used or contaminated lubricating oil (OLUC) is to carry out its reverse logistics through its re-refining. This study aimed to evaluate the OLUC's reverse logistics process in Poços de Caldas-MG municipality. For this purpose, the technical procedures used were bibliography research, technical visit and interviews. The analysis of this process pointed to an opportunity for improvement, that is changing the place of the pre-refining tests, which could be done at the origin of the collect (in Poços de Caldas) and no longer at the end (at the re-refiner). It was also identified the possibility of a junior company from the Federal University of Alfenas - Poços de Caldas campus to carry out the tests necessary for OLUC's ability to re-refining. Such proposal means a gain for all parts of the product chain: producers, consumers, collectors, re-refiners, the academic community, and of course, the environment.
\end{abstract}

Keywords:

Reverse logistic. Used or contaminated lubricating oils. Re-refining. Junior company.

\section{Como você deve citar?}

PASCOAL, Erik Telles; RIBEIRO, Lara Nabak Maroti; MENDES, Rafael. Proposta de melhoria no processo de logística reversa de óleos lubrificantes usados ou contaminados. Cadernos UniFOA, Volta Redonda (RJ), v. 16, n. 46, p. 1-12, ago, 2021. 


\section{INTRODUÇÃO}

Atualmente, todos os atores das cadeias produtiva e consumista de produtos acabados têm se preocupado, cada vez mais, com a questão do resíduo ou refugo ao final de sua vida útil. Um desses produtos é o óleo lubrificante que, além da extensa aplicação, gera também resíduo com um potencial altamente poluidor.

Automóveis, ônibus, caminhões, barcos, trens, entre outros tipos de meios de transportes, têm algo em comum: dependem da lubrificação, principalmente na parte dos motores, para o perfeito funcionamento. Os responsáveis por essa função são os óleos lubrificantes (COMPER; SOUZA; CHAVES, 2016; BOADU et al., 2019; MACHADO; FERES; GONÇALVES, 2019).

A coleta de óleos lubrificantes usados ou contaminados (OLUC) demanda grande cuidado, uma vez que esse produto é extremamente poluidor devido à sua composição química.

No Brasil, os OLUCs não podem ser depositados em qualquer lugar, tendo assim, uma única destinação legalmente adequada: o rerrefino (COMPER; SOUZA; CHAVES, 2016). O OLUC deve ser encaminhado para o rerrefino por meio de coletores credenciados pela Agência Nacional do Petróleo, Gás Natural e Biocombustíveis (ANP).

O rerrefino é a reintegração das propriedades iniciais dos óleos lubrificantes, possibilitando a recuperação entre $80 \%$ e $85 \%$ de óleo básico e servindo de matéria-prima novamente para novos produtos (BOADU et al., 2019; BHONGADE; PATIL; BHARGAVA, 2019). Porém, para que esse processo seja feito, é necessária a implementação da logística reversa, importante instrumento para gerenciar resíduos perigosos, de maneira a propiciar a reutilização de seus componentes ou uma destinação apropriada (COMPER; SOUZA; CHAVES, 2016; MACHADO; FERES; GONÇALVES, 2019; BANIHASHEMI; FEl; CHEN, 2019). Sua aplicação é regulamentada pela Política Nacional dos Resíduos Sólidos (PNRS), que define que os fabricantes, importadores, distribuidores e comerciantes de resíduos e embalagens são obrigados construir e efetivar sistemas de logística reversa (BRASIL, 2010; 2017; ANDRADE et al., 2018).

Nesse contexto, analisar a logística reversa de óleos lubrificantes usados ou contaminados é importante para que se avalie sua destinação final e, dessa forma, evitar desperdícios, como custos de transporte, de armazenagem, bem como eliminar ou diminuir os riscos ambientais causados por esse produto (SCHUELTER; FERNANDES; TAGLIALENHA, 2016; ANDRADE et al., 2018).

Assim, este artigo teve como objetivo geral avaliar o processo de logística reversa dos óleos lubrificantes usados ou contaminados no município de Poços de Caldas-MG. Durante a análise, foi identificada uma possibilidade de melhoria desse processo por meio da realização dos testes de pré-rerrefino do OLUC na origem de sua coleta, e não em seu destino final. A proposta em estudo é que esses testes possam ser realizados pela empresa júnior vinculada à Universidade Federal de Alfenas (UNIFAL) - campus de Poços de Caldas.

O presente artigo está dividido nas seguintes seções além da introdução: na seção 2 , são apresentados os referenciais teóricos aplicáveis ao tema em estudo; na seção 3, é abordada a metodologia de pesquisa utilizada no artigo; a seção 4 tem como finalidade apresentar os resultados e discussões do tema estudado e; por fim, na seção 5, são apresentadas as considerações finais deste artigo e as propostas para futuros trabalhos. 


\section{FUNDAMENTAÇÃO TEÓRICA}

Nesta seção, são apresentados os referenciais teóricos (óleo lubrificante usado e contaminado (OLUC), logística reversa, processo de rerrefino e empresa júnior), relevantes para o contexto do estudo.

\section{1 Óleo lubrificante usado ou contaminado (OLUC)}

Ao longo da utilização dos óleos lubrificantes, diversos fatores podem influenciar a alteração da sua viscosidade e da sua eficiência, perdendo, assim, suas propriedades iniciais. Quando isso ocorre, o óleo precisa ser trocado por um novo. 0 óleo que é extraído do motor ou qualquer outro equipamento é chamado de óleo lubrificante usado ou contaminado (OLUC), popularmente conhecido como "óleo queimado".

Por conter inúmeros elementos tóxicos (como chumbo, cromo, cádmio e arsênio), provenientes da fórmula original e oriundos do próprio motor ou equipamento, o óleo lubrificante usado ou contaminado é considerado um resíduo altamente perigoso, tanto por fazer mal à saúde humana quanto por trazer riscos ao meio ambiente (DEMAJOROVIC; SENCOVICI, 2015; PINHEIRO et al., 2017; BOADU et al., 2019; MACHADO; FERES; GONÇALVES, 2019).

Mesmo sendo resíduo, o OLUC não pode ser descartado em qualquer lugar. No Brasil, a Resolução $n^{\circ} 362 / 2005$ do Conselho Nacional do Meio Ambiente (CONAMA) dispõe sobre o recolhimento, coleta e destinação final do OLUC. A prática tecnicamente recomendada para evitar a contaminação ambiental é o envio do OLUC para reciclagem e recuperação de seus componentes úteis, por meio de um processo industrial conhecido como rerrefino (BRASIL, 2005; DEMAJOROVIC; SENCOVICI, 2015; ANP, 2017; MACHADO; FERES; GONÇALVES, 2019).

\subsection{Logística Reversa}

A logística direta ou tradicional é responsável por comprar, armazenar e distribuir materiais e produtos acabados em toda linha de produção, em um menor custo possível e a um prazo necessário, incluindo também todas as formas de movimentação de produtos e informações (MUNIZ; BRAGA, 2015; MACHADO; FERES; GONÇALVES, 2019).

Já a logística reversa, envolve todas as operações relacionadas à reutilização de produtos e materiais, desde o consumidor final até o fornecedor, na busca de uma reintegração a processos produtivos sustentáveis, a fim de recuperar valor ou fazer uma apropriada disposição ambiental (MACHADO; FERES; GONÇALVES, 2019; BANIHASHEMI; FEl; CHEN, 2019). A Figura 1 faz uma comparação entre os fluxos logísticos tradicional e reverso. 
Figura 1 - Ciclo logístico tradicional X ciclo logístico reverso

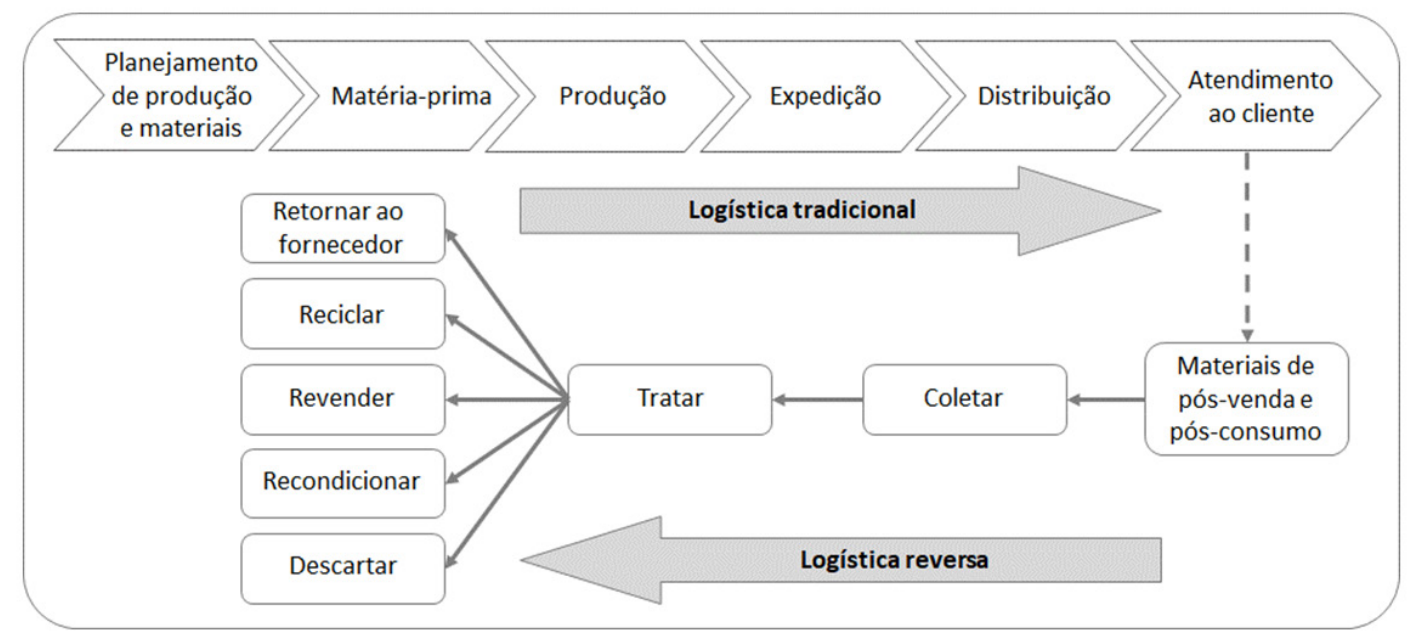

Fonte: Adaptado pelos autores de Stocher et al. (2019).

A logística reversa do OLUC é um importante instrumento de desenvolvimento econômico para o país, pois, dessa maneira, é possível retornar com o lubrificante pós-consumo ao início da cadeia produtiva, por meio do processo de rerrefino.

A PNRS dá ênfase em especial à responsabilidade compartilhada dos atores envolvidos no ciclo do OLUC. São cinco categorias de atores que participam desde a coleta até a destinação adequada do OLUC: Produtores e Importadores, Revendedores, Geradores, Coletores e Rerrefinadores (BRASIL, 2010).

\subsection{Rerrefino}

O rerrefino de óleo lubrificante usado ou contaminado (OLUC) é um processo industrial de remoção de contaminantes e de aditivos que transforma o óleo usado em óleo básico novamente (BRASIL, 2009; DEMAJOROVIC; SENCOVICI, 2015; BHONGADE; PATIL; BHARGAVA, 2019).

O rerrefino 'fecha" o ciclo de vida do OLUC e, além de evitar que esse resíduo perigoso seja descartado no meio ambiente, proporciona dois importantes resultados: preservação dos recursos naturais e reabastecimento do mercado de óleos básicos. O rerrefino é o método ambientalmente mais seguro para a reciclagem do OLUC, e, portanto, a melhor alternativa de gestão ambiental desse tipo de resíduo (BRASIL, 2009).

Embora cada uma das rerrefinadores possam ter diferentes tecnologias, o processo de rerrefino do OLUC é basicamente o mesmo para todas, sendo constituído de sete etapas: Desidratação, Craqueamento, Resfriamento, Sulfonação, Decantação, Clarificação e Filtração (SINDIRREFINO, 2019).

A primeira etapa é a Desidratação, que consiste na retirada de toda a umidade do material. Logo em seguida, é feito o Craqueamento, no qual o material é submetido a temperaturas elevadas $\left(340^{\circ} \mathrm{C}\right)$, para que sejam destruídos os aditivos e todas as substâncias sintéticas provenientes do desgaste do óleo lubrificante.

Após o Craqueamento, o material, passa por um trocador de calor para se resfriar. Ao término do Resfriamento, o material segue para a Sulfonação, momento em que recebe um banho de ácido sulfúrico, para que sejam retirados alguns componentes oxidados ainda remanescentes após o Craqueamento. Após a Sulfonação, o material é bombeado para um decantador, onde ocorre a Decantação, processo que leva algumas horas, na qual todas as impurezas que foram craqueadas na primeira fase se decantam. 
A próxima etapa é a Clarificação, processo em que a temperatura volta a aumentar e, ao mesmo tempo, o material recebe vácuo e vapor, para que, além de retirar o restante das impurezas, também se retire os materiais leves (combustíveis que se misturam dentro do motor automotivo) e a acidez do material. Após a Clarificação, o material segue para a última etapa: a Filtração.

Na Filtração, o material de interesse é filtrado por filtros prensa, para separar o óleo de outros resíduos. Após essa última etapa, o óleo mineral acabado é armazenado em tanques e estão prontos para serem transportados às fábricas de lubrificantes. A Figura 2 apresenta de forma esquemática todo o processo de rerrefino de OLUC.

Figura 2 - Fluxograma do processo de rerrefino do OLUC

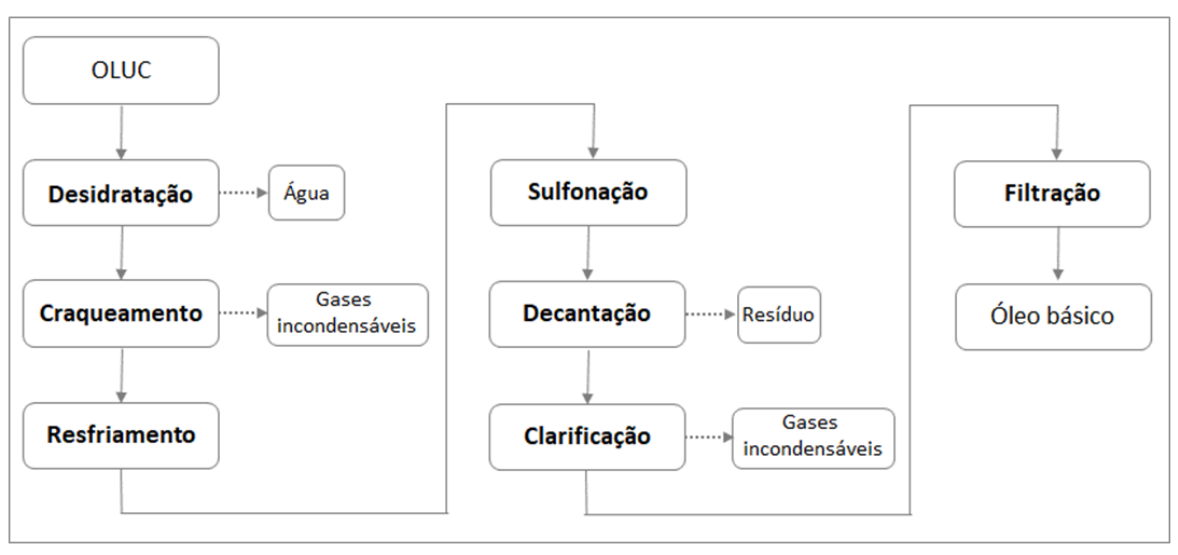

Fonte: Adaptado pelos autores de Sindirrefino (2019).

Conforme previsto na Resolução n 19/2009, da ANP, a atividade econômica de reciclagem do OLUC (Rerrefino) é considerada uma atividade de utilidade pública. 0 exercício dessa atividade depende de uma autorização expedida pelo órgão regulador da indústria do petróleo, desde que atendidos os requisitos legais previstos na referida Resolução (BRASIL, 2009). De acordo com a ANP (2019), as principais rerrefinadoras responsáveis pela coleta de OLUC, no Brasil, estão representadas na Figura 3.

Figura 3 - Market-Share nacional dos coletores de óleo lubrificante usado ou contaminado

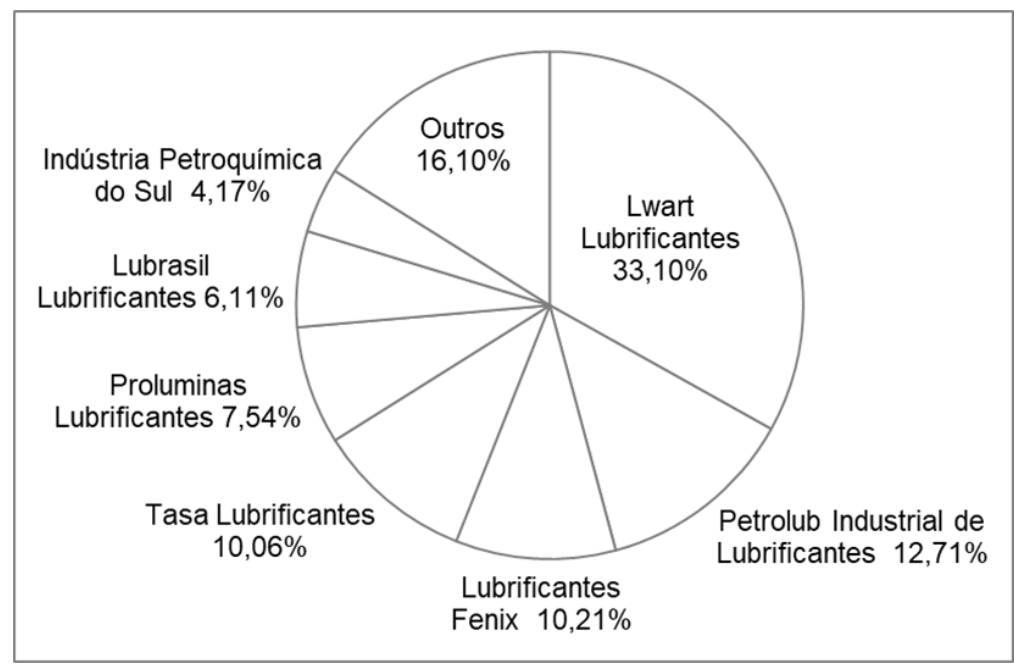

Fonte: Adaptado pelos autores de ANP (2019) 


\subsection{Os testes de pré-rerrefino}

A finalidade das análises do OLUC antes do rerrefino é para se verificar o teor de água e de contaminantes leves, além de determinar a presença de material saponificável nas amostras que possam inviabilizar a reciclagem. Os principais testes de pré-rerrefino são os seguintes:

- O Teste de Pingo é feito através da pipetagem de uma gota da amostra de OLUC em uma folha de papel filtro. A cor dessa gota é comparada a olho nu com uma tabela de parâmetros definida para esse tipo de teste e, assim determinar se a amostra é "boa" ou "ruim". Se a cor da gota for escura e uniforme, é indício de que o OLUC está homogêneo. Caso se perceba a formação de um círculo claro ao redor da gota escura é indício da presença de contaminantes no OLUC.

- O Teste de Saponificação é realizado por meio do aquecimento da amostra de OLUC sob agitação até uma temperatura de $200^{\circ} \mathrm{C}$ e, após o resfriamento em banho-maria, até a temperatura ambiente. Esse teste serve para verificar se a amostra "saponificou" ou "não saponificou". A saponificação evidencia qualitativamente a presença de óleo vegetal na amostra de OLUC, caracterizada quando se tem o aumento de viscosidade da amostra, formando uma crosta amarela nas paredes internas do béquer. A presença de óleo vegetal é indesejada, pois prejudica o rerrefino do OLUC.

- O Teste de Destilação de Água e Hidrocarbonetos Leves consiste em um processo que tem como objetivo identificar o teor de água e contaminantes leves presentes na amostra do OLUC. Dependendo do percentual de água e contaminantes leves encontrados na amostra, o processo de reciclagem do OLUC torna-se inviável devido à alteração de temperatura em um dos processos de rerrefino.

O Quadro 1 sintetiza as principais características e parâmetros dos três testes de pré-rerrefino do OLUC.

Quadro 1 - Testes de pré-rerrefino do OLUC.

\begin{tabular}{|l|l|l|l|}
\hline \multicolumn{1}{|c|}{ Testes } & \multicolumn{1}{|c|}{ Objetivo } & \multicolumn{1}{c|}{ Método } & \multicolumn{1}{c|}{ Parâmetros } \\
\hline Teste de Pingo & $\begin{array}{l}\text { Determinação da presença de } \\
\text { contaminantes na amostra do } \\
\text { OLUC }\end{array}$ & $\begin{array}{l}\text { Percolação em papel } \\
\text { semipermeável (Teste } \\
\text { qualitativo) }\end{array}$ & Pingo: bom / ruim \\
\hline Teste de Saponificação & $\begin{array}{l}\text { Determinação da presença } \\
\text { de material saponificável na } \\
\text { amostra do OLUC }\end{array}$ & $\begin{array}{l}\text { Aquecimento e agitação da } \\
\text { amostra de OLUC e depois } \\
\text { resfriamento (Teste qualitativo) }\end{array}$ & $\begin{array}{l}\text { Aumento da viscosidade: } \\
\text { sim / não }\end{array}$ \\
\hline $\begin{array}{l}\text { Teste de Destilação de Água } \\
\text { e Hidrocarbonetos Leves }\end{array}$ & $\begin{array}{l}\text { Determinação do percentual } \\
\text { de água e percentual de } \\
\text { hidrocarbonetos leves } \\
\text { presentes na amostra do OLUC }\end{array}$ & $\begin{array}{l}\text { Destilação simples à pressão } \\
\text { atmosférica e temperatura de } \\
\text { 280C, conforme ASTM D1744 }\end{array}$ & $\begin{array}{l}\text { Água: máximo 7\% } \\
\text { Hidrocarbonetos leves: } \\
\text { máximo 2\% }\end{array}$ \\
\hline
\end{tabular}

Fonte: Adaptado pelos autores de Sindirrefino (2019).

\subsection{Empresa Júnior da Universidade Federal de Alfenas (UNIFAL)}

De acordo com o Serviço Brasileiro de Apoio às Micro e Pequenas Empresas (SEBRAE), uma empresa júnior é caracterizada como

Uma associação civil sem fins lucrativos, formada e gerida por alunos de um curso superior, que tem como objetivos: fomentar o aprendizado prático do universitário em sua área de atuação; aproximar 
o mercado de trabalho das academias e os próprios acadêmicos; elaborar projetos de consultoria na área de formação dos alunos, entre outros (SEBRAE, 2019, p.1).

A Saber Engenharia Jr., empresa júnior da UNIFAL, campus de Poços de Caldas, foi criada em 25 de junho de 2015 e tem a capacidade de contemplar as diversas áreas das Engenharias, sendo capaz de desenvolver projetos conceituais, estudos de viabilidade, projetos básicos e executivos para as Engenharias de Minas, Química e Ambiental.

Um dos principais objetivos é de adquirir habilidades além da sala de aula como, o trabalho em equipe, técnicas de liderança, experiência em gerenciamento, administração, lidar com finanças e interações relacionadas ao mercado de trabalho.

Com a qualificação multidisciplinar e a vocação interdisciplinar do corpo docente da UNIFAL, a Saber Engenharia Jr. se insere no mercado como uma empresa ideal e apta a prestar serviços de consultoria especializada (ARAÚJO, 2015).

\section{METODOLOGIA}

Esta seção apresenta a classificação da pesquisa e a metodologia que foi desenvolvida neste estudo.

\subsection{Classificação da pesquisa}

De acordo com Gil (2017), a classificação da pesquisa pode ser realizada sob vários aspectos: natureza, objetivos, abordagem do problema e procedimentos técnicos.

Particularmente, este artigo, do ponto de vista de sua natureza, foi classificado como uma pesquisa aplicada, pois tem a finalidade prática de estudar a logística reversa do OLUC e propor melhorias para os problemas encontrados.

Do ponto de vista de seus objetivos, este estudo foi classificado como uma pesquisa exploratória e descritiva, uma vez que busca maior conhecimento sobre o tema escolhido, por meio da análise, compreensão e descrição da logística reversa do OLUC e, assim, identifica possibilidades de melhoria no processo.

Quanto à forma de abordagem do problema, o presente estudo é considerado uma pesquisa qualitativa, pois sua ênfase está na interpretação dos processos e nos seus significados com o intuito de se chegar a uma conclusão.

Já os procedimentos técnicos utilizados neste estudo, foram a pesquisa bibliográfica e visita técnica.

\subsection{Procedimentos técnicos}

Na primeira etapa, foi realizada uma revisão bibliográfica a respeito do tema de logística reversa de óleos lubrificantes usados ou contaminados, abrangendo, não somente trabalhos técnicos, mas também a legislação em vigor, conforme apresentado no Quadro 2. Buscou-se artigos acadêmicos recentes e publicados em periódicos nacionais e internacionais, demonstrando-se, assim, a relevância e a contemporaneidade do assunto. 
Quadro 2 - Síntese da revisão bibliográfica.

\begin{tabular}{|l|l|}
\hline Termos da pesquisa: & Principais fontes pesquisadas: \\
\hline $\begin{array}{l}\text { Óleo Lubrificante Usado (Used Lubricating Oil), Logística } \\
\text { Reversa do Óleo Lubrificante (Reverse Lubricant Oil Logistics), } \\
\text { Logística Reversa (Reverse Logistics), Rerrefino de Óleo } \\
\text { Lubrificante (Re-Refining of Lubricating Oil) }\end{array}$ & $\begin{array}{l}\text { Legislação, Portal de Periódicos da CAPES, periódicos } \\
\text { nacionais e internacionais especializados e livros }\end{array}$ \\
\hline Critérios de inclusão: & Critérios de exclusão: \\
\hline $\begin{array}{l}\text { - Leis, artigos acadêmicos, livros, capítulos de livros, teses, } \\
\text { dissertações e relatórios de pesquisas }\end{array}$ & Artigos de jornais, revisões e artigos de opinião editorial \\
\hline
\end{tabular}

Fonte: Elaborado pelos autores (2019).

Na segunda etapa, foi realizada uma visita técnica à sexta maior rerrefinadora do país, localizada no município de Piracicaba, no estado de São Paulo. Durante a visita, foi possível compreender todo processo de logística reversa do OLUC: coleta, transporte, testes e rerrefino. Foi também realizada uma entrevista com o responsável pela Gestão de Produção e Aspectos Ambientais da empresa, que, além de esclarecer dúvidas sobre o processo de logística reversa do OLUC, permitiu identificar as oportunidades de melhoria nesse processo e justificar o propósito deste estudo.

Como última etapa, foi estudado, junto à empresa júnior Saber Engenharia Jr. e à Universidade Federal de Alfenas - campus de Poços de Caldas, a viabilidade técnica e operacional para a realização dos testes de pré-rerrefino do OLUC coletado no município de Poços de Caldas-MG nos laboratórios da Universidade.

Foram realizadas reuniões com os membros da empresa júnior, a fim de levantar dados quanto à capacidade de atender à demanda de testes e, assim, ter um posicionamento sobre a possibilidade de se fazer propostas aos coletores de OLUC do município de Poços de Caldas-MG.

\section{$4 \quad$ RESULTADOS E DISCUSSÕES}

Para uma melhor compreensão, as informações desta seção foram separadas em duas subseções.

\subsection{A Rerrefinadora e o processo de rerrefino de OLUC}

A rerrefinadora estudada é responsável por fazer a maior parte da coleta e do rerrefino de OLUC do município de Poços de Caldas-MG.

Na visita técnica, foi possível levantar dados sobre o processo de logística reversa de OLUC do município de Poços de Caldas-MG. O OLUC da cidade é coletado em sessenta e cinco postos de coleta e/ou fontes geradoras (como oficinas mecânicas, de troca de óleos, postos de combustíveis, etc.) e o volume mensal coletado e transportado de OLUC de Poços de Caldas-MG para Piracicaba-SP é de 23.060 litros, totalizando, em média, 55 caminhões (de 5.000 litros) por ano.

A coleta se inicia quando as fontes geradoras de óleo lubrificante entram em contato com a empresa para fazer a coleta de OLUC. Posteriormente, antes de carregar os caminhões de coleta, os coletores fazem uma "verificação a olho nu", para identificar se há uma grande quantidade de água ou se a amostra tem uma cor diferente do habitual do OLUC.

Entretanto essas "verificações a olho nu" não são totalmente precisas e, por isso, quando os caminhões carregados de OLUC chegam às rerrefinadoras, elas fazem testes mais precisos do OLUC, 
conforme detalhado na seção 2.4, para se verificar a "qualidade" antes de iniciar o seu processo de reciclagem. Caso a amostra do OLUC seja reprovada em um dos testes, todo o lote é transportado de volta à sua origem, ou seja, é devolvido aos coletores.

De acordo com a empresa, o percentual de reprovação dos caminhões pode chegar a $10 \%$ do total, ou seja, em média, seis caminhões de 5.000 litros de OLUC são reprovados anualmente. Isso acarreta na devolução do OLUC contido no caminhão, ocasionando novos custos logísticos, perda de tempo e, principalmente, riscos ambientais mediante um possível acidente no retorno desse caminhão aos coletores.

Com base nesses dados, torna-se bastante viável e de interesse de toda a cadeia de logística reversa de OLUC que os testes de pré-rerrefino sejam realizados na origem da coleta, o que evitaria o transporte desnecessário de um volume que não estaria apto para o processo de rerrefino. Mais especificamente, o que está sendo proposto é que tais análises sejam realizadas, não ao final do processo logístico em Piracicaba-SP, mas sim na origem de coleta do OLUC, ou seja, na cidade de Poços de Caldas-MG pela empresa júnior da UNIFAL.

Em termos quantitativos, de acordo com a Rerrefinadora, o custo para a realização dos três testes de pré-rerrefino é de, aproximadamente, $R \$ 5,00$, ou seja, a receita anual para a empresa júnior com os testes seria de, aproximadamente, $R \$ 275,00$ (equivalente aos 55 caminhões). Porém, o ganho é bem maior, pois é necessário incluir a economia do transporte (ida e volta) dos caminhões que tiveram o OLUC rejeitado para o rerrefino. 0 custo do transporte, segundo a Rerrefinadora, é em média R\$600,00 por caminhão, sem contabilizar o desgaste dos veículos e outras despesas. Dessa forma, a estimativa mínima de ganho anual de transporte seria em torno de $\mathrm{R} \$ 3.000,00$, considerando-se a média de cinco caminhões rejeitados.

Apesar dos valores monetários serem modestos é importante ressaltar que, sem a circulação desnecessária dos caminhões rejeitados, são evitados potenciais acidentes que poderiam acarretar grandes impactos ambientais.

\subsection{Viabilidade dos testes na empresa júnior}

Do ponto de vista técnico, foi identificado que os laboratórios possuem todos os recursos e equipamentos necessários para a realização dos três testes (Teste de Pingo, Teste de Saponificação e o Teste de Destilação de Água e Hidrocarbonetos Leves).

Do ponto de vista operacional, foi confirmada a viabilidade da empresa júnior prestar esse tipo de serviço, uma vez que já atua em algo semelhante, como na análise de resíduos oriundos de postos de combustíveis e oficinas mecânicas em Poços de Caldas-MG.

Outro ponto favorável é que essa nova possibilidade de prestação de serviço poderia aumentar os recursos para investimento na estrutura da própria empresa júnior, além de desenvolver e capacitar os seus membros para futuras oportunidades profissionais.

\section{CONSIDERAÇÕES FINAIS}

O presente estudo apresenta uma abordagem extremamente importante e atual a respeito do destino, após uso primário de um produto com grande potencial poluidor: o óleo lubrificante. Este estudo enriquece a literatura acerca do tema logística reversa, que adquire cada vez mais espaço no cenário nacional e mundial. 
Após a análise dos dados levantados in loco na sexta maior rerrefinadora do país, foi observado oportunidade de melhoria no processo de logística reversa dos óleos lubrificantes usados ou contaminados no município de Poços de Caldas-MG, que é a realização dos testes de pré-rerrefino na origem da coleta.

A proposta de se fazer tal análise no próprio município onde é coletado o OLUC atua como um plano de contingência efetivo para os casos em que o volume de OLUC a ser rerrefinado não atende às especificações mínimas exigidas para o seu rerrefino. Nesse caso, o óleo rejeitado na rerrefinadora é transportado de volta para os coletores. Com os testes pré-rerrefino realizados na origem, esse transporte não será mais necessário. Além disso, a proposta possibilita uma estimativa de economia financeira dos gastos de transporte dos caminhões rejeitados, e, ainda, gera uma fonte de renda para a empresa júnior, além, é claro, dos potenciais ganhos para o meio ambiente.

A ideia de se fazer tais testes por meio de uma empresa júnior garante um trabalho de qualidade, realizado por pessoas capacitadas e promove o desenvolvimento profissional e social dos membros da empresa.

Os pontos mencionados acima justificam a realização do presente estudo, abrindo um leque de oportunidades a serem exploradas pela Universidade em prol da comunidade e do meio ambiente, referentes ao assunto de logística reversa de óleos lubrificantes usados ou contaminados.

\section{REFERÊNCIAS}

ANDRADE, E. T.; AMÂNCIO, M. E.; JESUS, T. L.; REZENDE, R. P.; SOUSA, A. C. D.; MENEZES, F. S. Reverse Logistics in the Disposal of Residual Lubricating Oil. Theoretical and Applied Engineering. ISSN: 25943863 , v. 2, n. 4, pp. 1-5, 2018. DOI: https://doi.org/10.31422/taae.v2i4.14

AGÊNCIA NACIONAL DO PETRÓLEO, GÁS NATURAL E BIOCOMBUSTÍVEIS. Relatório Individual de Coleta de OLUC. Superintendência de Abastecimento, jun. 2017. Disponível em: http://www.anp.gov.br/images/ DISTRIBUICAO_E_REVENDA/Lubrificantes/Dados_mercado/relatorio_coleta_OLUC1.1.pdf Acesso em: 05 dez. 2019.

AGÊNCIA NACIONAL DO PETRÓLEO, GÁS NATURAL E BIOCOMBUSTÍVEIS. Boletim de Lubrificantes. Superintendência de Distribuição e Logística, ano 4, n. 32, set. 2019. Disponível em: http://www.anp. gov.br/arquivos/publicacoes/boletins-anp/lubrificantes/n32/2019-09-boletim-lubrificantes.pdf Acesso em: 06 dez. 2019.

ARAÚJO, A. C. Campus Poços inaugura a empresa "Saber Engenharia Jr.". Assessoria de Comunicação Social da Universidade Federal de Alfenas, jun. 2015. Disponível em: https://www.unifal-mg.edu.br/ comunicacao/campuspocosinauguraempresajr Acesso em: 07 dez. 2019.

BANIHASHEMI, T. A.; FEI, J.; CHEN, P. S. Exploring the relationship between reverse logistics and sustainability performance: A literature review. Modern Supply Chain Research and Applications. ISSN: 2631-3871. v. 1 n. 1, pp. 2-27, may. 2019. DOI: https://dx.doi.org/10.1108/MSCRA-03-2019-0009

BHONGADE, O.; PATIL, K.; BHARGAVA, R. Recent Methods Available for Re-Refining of Lubricating Oil: A Review. International Journal for Research in Applied Science \& Engineering Technology. ISSN: 23219653, v. 7, n. 5, Apr 2019. DOl: https://doi.org/10.22214/ijraset.2019.4190 
BOADU, K. O.; JOEL, O. F.; ESSUMANG, D. K.; EVBUOMWAN, B. O. A Review of Methods for Removal of Contaminants in Used Lubricating Oil. Chemical Science International Journal. ISSN: 2456-706X, v. 26, n. 4, pp. 1-11, 2019. DOI: http://dx.doi.org/10.9734/CSJI/2019/v26i430101

BRASIL. Resolução $n^{\circ}$ 362, de 23 de junho de 2005. Dispõe sobre o recolhimento, coleta e destinação final de óleo lubrificante usado ou contaminado. Diário Oficial da União. Brasília, DF, 27 jun. 2005. Disponível em: http://www2.mma.gov.br/port/conama/legiabre.cfm?codlegi=466 Acesso em: 07 dez. 2019.

BRASIL. Resolução n 19, de 18 de junho de 2009. Estabelece os requisitos necessários à autorização para o exercício da atividade de rerrefino de óleo lubrificante usado ou contaminado. ANP. Diário Oficial da União. Brasília, DF, 18 jun. 2009. Disponível em: http://legislacao.anp.gov.br/?path=legislacao-anp/ resol-\%20anp/2009/junho\&item=ranp-19--2009 Acesso em: 07 dez. 2019.

BRASIL. Lei n 12.305 , de 2 de agosto de 2010. Institui a Política Nacional de Resíduos Sólidos; altera a Lei no 9.605, de 12 de fevereiro de 1998; e dá outras providências. Diário Oficial da União. Brasília, DF, 03 ago. 2010. Disponível em: http://www.planalto.gov.br/ccivil_03/_ato2007-2010/2010/lei//12305.htm Acesso em: 06 dez. 2019.

BRASIL. Decreto $n^{\circ}$ 9.177, de 23 de novembro de 2017. Regulamenta o art. 33 da Lei $n^{\circ} 12.305$, de 2 de agosto de 2010, que institui a Política Nacional de Resíduos Sólidos, e complementa os art. 16 e art. 17 do Decreto $n^{\circ} 7.404$, de 23 de dezembro de 2010 e dá outras providências. Diário Oficial da União. Brasília, DF, 24 out. 2017. Disponível em: http://www.planalto.gov.br/ccivil_03/_Ato2015-2018/2017/ Decreto/D9177.htm Acesso em: 06 dez. 2019.

COMPER, I. C.; SOUZA, F. O.; CHAVES, G. L. D. Caracterização e Desafios da Logística Reversa de Óleos Lubrificantes. Revista em Gestão, Inovação e Sustentabilidade. ISSN: 2447-7648, v. 2, n. 1, pp.131-155, jun. 2016. DOI: http://dx.doi.org/10.18472/ReGIS.v2n1.2016.18431

DEMAJOROVIC, J.; SENCOVICI, L. A. Entraves e perspectivas para a logística reversa do óleo lubrificante e suas embalagens. Revista de Gestão Ambiental e Sustentabilidade. ISSN: 2316-9834, v. 4, n. 2, pp.83101, mai-ago 2015. DOI: http://dx.doi.org/10.5585/geas.v4i2.167

GIL, A. C. Como Elaborar Projetos de Pesquisa. 6. ed. São Paulo: Atlas, 2017.

MACHADO, G. C.; FERES, P. P.; GONÇALVES, M. F. S. Reverse logistics: feasibility analysis of the collection and restitution of lubricating oil used or contaminated. Journal of Engineering and Technology for Industrial Applications. ISSN: 2447-0228, v. 5, n. 17, pp. 62-67, mar. 2019. DOI: https://dx.doi. org/10.5935/2447-0228.20190009

MUNIZ, I. C.; BRAGA, R. M. Q. L. O Gerenciamento de Óleos Lubrificantes Usados ou Contaminados e suas Embalagens: Estudo de Caso de uma Empresa de Logística na Região Norte do Brasil. Revista Eletrônica Sistemas \& Gestão, ISSN: 1980-5160, v. 10, n. 3, pp. 442-457, jan. 2015. DOI: https://doi. org/10.7177/sg.2015.V10.N3.A8

PINHEIRO, C. T.; ASCENSÃO, V. R.; CARDOSO, C. M.; QUINA, M. J.; GANDO-FERREIRA, L. M. An overview of waste lubricant oil management system: Physicochemical characterization contribution for its improvement. Journal of Cleaner Production. ISSN: 0959-6526. v. 150, pp. 301-308, may. 2017. DOI: https://doi.org/10.1016/j.jclepro.2017.03.024 
SCHUELTER, L. M.; FERNANDES, C. W. N.; TAGLIALENHA, S. L. S. Óleos Lubrificantes Automotivos Residuais: Um Estudo de Caso em Logística Reversa. Colloquium Exactarum. ISSN: 2178-8332, v. 8, n. 2, pp. 69-84, 25 abr. 2017. DOI: http://dx.doi.org/10.5747/ce.2016.v08.n2.e156

SEBRAE. Empresa Júnior: 0 que é? Como Funciona? Disponível em: https://www.sebrae.com.br/sites/ PortalSebrae/ufs/ap/artigos/empresa-junior-o-que-e-e-como-funciona,e3a048ae422fe510VgnVCM100 0004c00210aRCRD. Acesso em: 07. dez. 2019.

SINDIRREFINO. Sindicato Nacional da Indústria do Rerrefino de Óleos Minerais Processo Industrial/ Rerrefino, 2019. Disponível em: https://www.sindirrefino.org.br/rerrefino/processo-industrial Acesso em: 04 dez. 2019.

STOCHER, F. M.; SILVA, M. L.; CAPPELLARI, G.; CASSANEGO JÚNIOR, P. V. A. Logística Reversa no Setor Farmacêutico. Revista Produção Online. ISSN: 1676-1901, v. 19, n. 3, pp. 1069-1093, 2019. DOI: https:// doi.org/10.14488/1676-1901.v19i3.3607 